DOI 10.37882/2500-3682.2020.11.06

\title{
ОСНОВНЫЕ МЕТОДОЛОГИЧЕСКИЕ ПОДХОДЫ К ИЗУЧЕНИЮ ОБРАЗА Я В ОТЕЧЕСТВЕННОЙ И ЗАРУБЕЖНОЙ ПСИХОЛОГИИ
}

\section{THE MAIN METHODOLOGICAL APPROACHES TO THE STUDY \\ OF THE SELF-IMAGE IN RUSSIAN AND FOREIGN PSYCHOLOGY}

\section{T. Gutova \\ Yu. Popova \\ V. Marukhno}

Summary: The article presents the results of a theoretical analysis of the problem of the image of the self in psychological science. The main methodological approaches to the definition of the concepts of "selfimage», "self-consciousness», "self-concept» in various psychological theories are analyzed. It is shown that the concepts of «self-image», "self-awareness", "self-concept» in most studies are interpreted as identical concepts. The formation and development of the image of the Self presupposes the presence of stages of its formation and structural components, which in a number of the authors' studies are designated in different ways. The formation of the self-image occurs mainly in adolescence, but the development of self-awareness does not stop there.

Keywords: self-image, Self-image structure, self-awareness, self-esteem, Self-concept of personality.
Гутова Тамара Сергеевна

К.nсх.н., дочент, Кубанский государственный медицинский университет, Краснодар zhurzhu@mail.ru

Попова Юлия Ивановна

К.nсх.н., Кубанский государственный университет, Краснодар jeis@mail.ru

Марухно Василиса Михайловна

К.ю.н., Кубанский государственный медицинский университет, Краснодар vasilisa_amg@mail.ru

Аннотация: В статье представлены результаты теоретического анализа проблемы образа Я в психологической науке. Проанализированы основные методологические подходы к определению понятий «образ Я», «самосознание», «Я-концепция» в различных психологических теориях. Показано, что понятия «образ Я», «самосознание», «Я-концепция» в большинстве исследований трактуются как идентичные понятия. Формирование и развитие образа Я предполагает наличие этапов своего становления и структурных компонентов, которые в ряду исследований авторов обозначаются по-разному. Становление образа Я происходит преимущественно в подростковом возрасте, однако развитие самосознания на этом не прекращается.

Ключевые слова: образ Я, структура образа Я, самосознание личности, самооценка, Я-концепция личности.

по времени и по содержанию возникновения образов Я: настоящее Я - то, каким видит себя индивид в настоящий момент, динамическое Я - то, каким индивид поставил себе цель стать, фантастическое Я - то, каким следует быть, исходя из усвоенных норм и образцов, идеализированное Я - то, каким приятно видеть себя, будущее Я - то, каким по мнению, человека, он мог бы стать и изображаемое Я - те маски образы, которые индивид выставляет напоказ, чтобы скрыть своего настоящего Я [6].

Определенный вклад в исследования Я - концепции внесли представители гуманистической психологии, в частности К. Роджерс, рассматривавший ее как динамическое образование, которое складывается из представления о собственных характеристиках и способностях индивида, о возможностях взаимодействия его с другими людьми, которые могут иметь позитивную или негативную направленность. Всего К. Роджерс выделяет четыре параметра Я - концепции: реальное представление о себе, представление о своей социальной роли, представление о собственном физическом состоянии и здоровье, представление о своих целях и планах на будущее, тем самым объединяя внешне- и внутренне-на- 
правленные содержательные и временные характеристики. [6].

Р. Бернс также представляет Я - концепцию как иерархическую структуру, как «совокупность всех представлений индивида о самом себе, сопряженная с их оценкой». В связи с этим исследователем выделяются три составляющие Я - концепции: образ «Я» - когнитивный аспект, знания о собственной личности во всех областях и сферах; самооценка или принятие себя - совокупность оценочных характеристик, отношений к имеющейся о себе информации; поведенческие установки - действия, вызываемые образом и самооценкой и реализующиеся в общении с окружающими. Таким образом, мы видим, что Р. Бернс отводит самооценке роль эмоционально - ценностной структуры и считает ее средством и условием формирования Я - концепции $[1,5,7]$.

В отечественной психологии термин Я - концепция употребляется редко, в основном исследователи употребляют понятие образа «Я», самооценки и самосознания. Однако, до сих пор соотношение этих понятий изучено недостаточно, поэтому при изучении образа «Я» предлагаются структуры, в русле которых осуществлялись исследования данного феномена. Среди таких структурных компонентов авторами анализируются самосознание, самооценка, самоуважение, самопонимание и т.д. Проблемы самосознания, самооценки и их соотношения с образом Я рассматривали И.С. Кон, В.С. Мухина, В.В. Столин, Т.В. Дмитрова, Е.Т. Соколова, Ю.А. Рождественский, Л.В. Бороздина[2,3,4,5,6,7].

B.В. Столин при изучении самосознания обращает внимание на его уровневую структуру, при том каждый уровень имеет свою структуру и отражает тот или иной аспект образа Я. На органическом уровне самосознание отражает физический образ Я человека, включающий неосознанное, в основном только переживаемое отношение к себе, которое традиционно определяется как самочувствие. Самочувствие можно рассматривать как некоторые обобщающие характеристики (недомогание, ощущение бодрости, легкости, внутреннего благополучия), иными словами, ощущение физиологической и психологической комфортности. Следовательно, самочувствие - биологический аналог самоотношения человека. Хотя самочувствие не определяет поступки человека, но в то же время образ Я может влиять на выбор того или иного поступка и на форму поведения [7].

Вступая в разнообразные отношения с другими людьми, человек ориентируется на определенные нормы, правила, обычаи. Образ Я на индивидуальном уровне отражает степень соответствия-несоответствия человека требованиям, предъявленным ему обществом. Осознавая себя как социального индивида, человек ото- ждествляет себя с определенной группой людей - половой, возрастной, этнической, профессиональной и др. Идентифицируя себя с этими группами, индивид «смотрит» на себя глазами других, оценивая свои поступки с позиций той или иной группы. Понятие идентификации в психологическом смысле употребляется для обозначения механизма усвоения социальных ролей, стандартов поведения, основанных на их воспроизведении и копировании. Различными могут быть люди, с которыми отождествляет себя человек: родители, близкие, значимые другие, герои произведений литературы и искусства, а также представители животного мира. Идентификация может быть различной по полноте - сравнение по одному или нескольким признакам, качествам, может быть сознательной и неосознаваемой, иметь рациональный или эмоциональный характер.

Критериями личностного уровня самосознания являются свобода выбора и ответственность за него. Сам выбор из ряда возможностей предполагает отказ от чего-то ради более ценного и значимого. Его осуществление требует и различных личностных проявлений, иногда противоречащих друг другу (быть мягким и требовательным, принимать решения и быть осторожным, выбирать между профессиональным долгом и личными симпатиями).

Пока поступок не совершен, конфликтный смысл реально не возникает, хотя потенциально он существует (личность должна сделать выбор). Конфликтный смысл может восприниматься личностью сознательно как необходимость выбора либо переживаться как субъективная трудность в виде слабоосознанного ощущения внутреннего дискомфорта. Осознание и переживание личностью конфликтного смысла начинается после совершения поступка. Выбор личности приводит к тому или иному поступку, который, в свою очередь, вызывает конфликтный смысл «Я», запускающий работу самосознания. Ситуативный образ «Я», отражает столкновение различных жизненных отношений субъекта, столкновение его мотивов и деятельности. Таким образом, В.В. Столин рассматривает образ «Я» как структурный компонент самосознания и в этой структуре выделяет физический образ «Я», социальный образ «Я» и личностный образ «Я».

И.С. Кон и А.В. Петровский выделяют в структуре Я - концепции именно образ Я и предлагают его рассматривать как когнитивный компонент, включающий представления индивида о самом себе, о своих способностях, внешности и социальной значимости. Представления индивида о самом себе основываются, как правило, на объективном знании или субъективном мнении. Предметом восприятия человека могут стать, в частности, его тело, способности, его социальные отношения с други- 
ми людьми и множество других личностных проявлений. Конкретные способы самовосприятия, ведущие к формированию образа «Я», могут быть самыми разнообразными. Описывая самого себя, человек прибегает к каким - то абстрактным характеристикам, которые, как правило, не связаны с конкретным событием и таким образом человек пытается выразить основные характеристики своего самовосприятия. Эти характеристики составляют иерархию по значимости элементов самоописания, которая может меняться в зависимости от контекста, жизненного опыта человека или просто под влиянием ситуации и, в конечном итоге, сводится к формированию образа «Я», который по мнению авторов, не может быть исчерпывающим в течение всей жизни.

Интерес представляет собой концепция Л.В. Бороздиной, которая подчеркивает необходимость разделения трех образований: образа Я, самооценки и самоотношения. С точки зрения исследователя, образ Я не может быть сведен ни к самооценке, ни к устойчивому чувству индивида к себе, то есть самоотношению. Образ Я фиксирует знание субъекта о себе, будучи комплексом сведений человека о самом себе, а самооценка включает оценку самого себя с точки зрения определенных ценностей. Кроме этого, исследователь указывает на разновременность формирования компонентов самосознания и несовпадение их характеристик. Таким образом, Л.В. Бороздина приходит к выводу о том, образ Я является более ранним образованием, чем самооценка $[2,5,7]$.

Т. В. Дмитрова, изучая образ «Я», наибольшее внимание уделяет его социальному аспекту и указывает, что сфера социального образа Я у подростков когнитивно сложнее, чем у взрослых. Когнитивная сложность социального «Я» у подростков на протяжении ранней юности имеет относительно более статический характер. Позитивность как когнитивного, так и эмоционального компонентов социального «Я» у них более высокая, что свидетельствует о значимости этой сферы в их жизни. Социальное «Я», является для большинства подростков центральной, интегрирующей, существенной стороной личности, имеет для них чуть ли не наивысшую значимость, ценность, подлежит наибольшему осознанию, является предметом рефлексии, самовоспитания [3].

Е.Т. Соколова, наоборот, в своих исследованиях образа «Я», в большей мере описывает его телесный аспект и показывает роль индивидуально-личностных особенностей субъекта в процессе отражения им своих телесных качеств. Так, неудовлетворенность какими-то своими физическими данными фиксация на мнимом дефекте реальном или мнимом, повышенная значимость определенных частей тела или телесного облика в целом не- избежно влияют на представление о своем физическом «Я», на общий уровень самоприятия. Но в то же время само содержание физического образа «Я» и его структурные характеристики, в частности, определяют как частные самооценки, так целостное отношение к себе в виде самоприятия или самоотвержения [5,7].

Ю.А. Рождественский также указывает на значимость телесного потенциала в структуре образа Я у старшеклассников. В своем исследовании он показывает взаимосвязь между уровнем сформированности телесности и жизненными проектами старшеклассников. Исследователь выявил, что отсутствие или недостаточность опыта рефлексии своего телесного потенциала ведет к созданию жизненных проектов, лишенных надлежащей четкости, стабильности и структурированности. Таким образом, недооценка феномена телесности нередко приводит к укреплению ложных представлений о роли телесного образа Я в достижении личностью поставленной цели, а, следовательно, ее дальнейшего развития и становления [4].

Кроме этого, в психологии можно выделить ряд исследований, посвященных исследованию образа «Я» и его влияния на успешность обучения подростков. Переживание динамичности образа «Я» рассматривают как источник мотивации учения такие исследователи как Г.С. Абрамова, А.Б. Орлов, А.К. Маркова и др. Авторы считают, что негативный образ себя и недостаток недоверия ведут к снижению успеваемости подростка и в то же время, успехи и неудачи оказывают влияние на его образ себя, самодоверие и самопонимание [6, 7].

\section{Выво $\Delta ы$}

Таким образом, проведенный анализ литературы, посвященный исследованию образа «Я», обнаруживает отсутствие единого варианта интерпретации данного феномена в современной психологии, что вносит определенную путаницу, особенно когда речь идет о проведении экспериментальных исследований. Существующие определения можно разделить на три группы: 1) Образ Я интерпретируется как многоуровневая структура, в которой выделяются те или иные компоненты; 2) Образ Я рассматривается во взаимосвязи с самооценкой и самосознанием, при этом может выступать как элемент самооценки или как элемент самосознания; 3) Образ Я отождествляется с Я - концепцией. Наряду с этим, можно обобщить и выделить основные условия развития образа Я: интериоризация мнения окружающих людей, результаты конкретной деятельности, внешность и как ее следствие социальная значимость среди других, собственные ценности и идеалы, личностная рефлексия. 


\section{ЛИТЕРАТУРА}

1. Бернс Р. Развитие Я-концепции и воспитание/Р.Бернс-М.: Прогресс, 1986. - 422с.

2. Бороздина Л.В. Самооценка в разных возрастных группах: от подростков до престарелых / Л.В. Бороздина, 0.Н. Молчанова. - М., 2001.

3. Дмитрова Т.В. Образ "Я" как регулятор межличностных отношений в ранней юности: Дисс. ... канд. психол. наук / Т.В. Дмитрова. - К., 1993. - 187с.

4. Ложкин Г.В. Феномен телесности в я-структуре старшеклассников и содержании их жизненных проектов / Г.В. Ложкин, А.Ю. Рождественский // Психологический журнал. - 2004. - Т. 25, № 2. - С. 27-33.

5. Психология самосознания. Хрестоматия. - Самара: Изд. дом «БАХРАХ- М», 2000. - 672с.

6. Романова И.А. Основные направления исследования самопонимания в зарубежной психологии / И.А. Романова // Психологический журнал. - 2001, T. 22, № 1. - С.102-112

7. Самосознание и защитные механизмы личности. Хрестоматия. - Самара: Изд. дом «БАХРАХ- М», 2000. - 654 с.

○ Гутова Тамара Сергеевна (zhurzhu@mail.ru), Попова Юлия Ивановна (jeis@mail.ru),

Марухно Василиса Михайловна (vasilisa_amg@mail.ru).

Журнал «Современная наука: актуальные проблемы теории и практики»

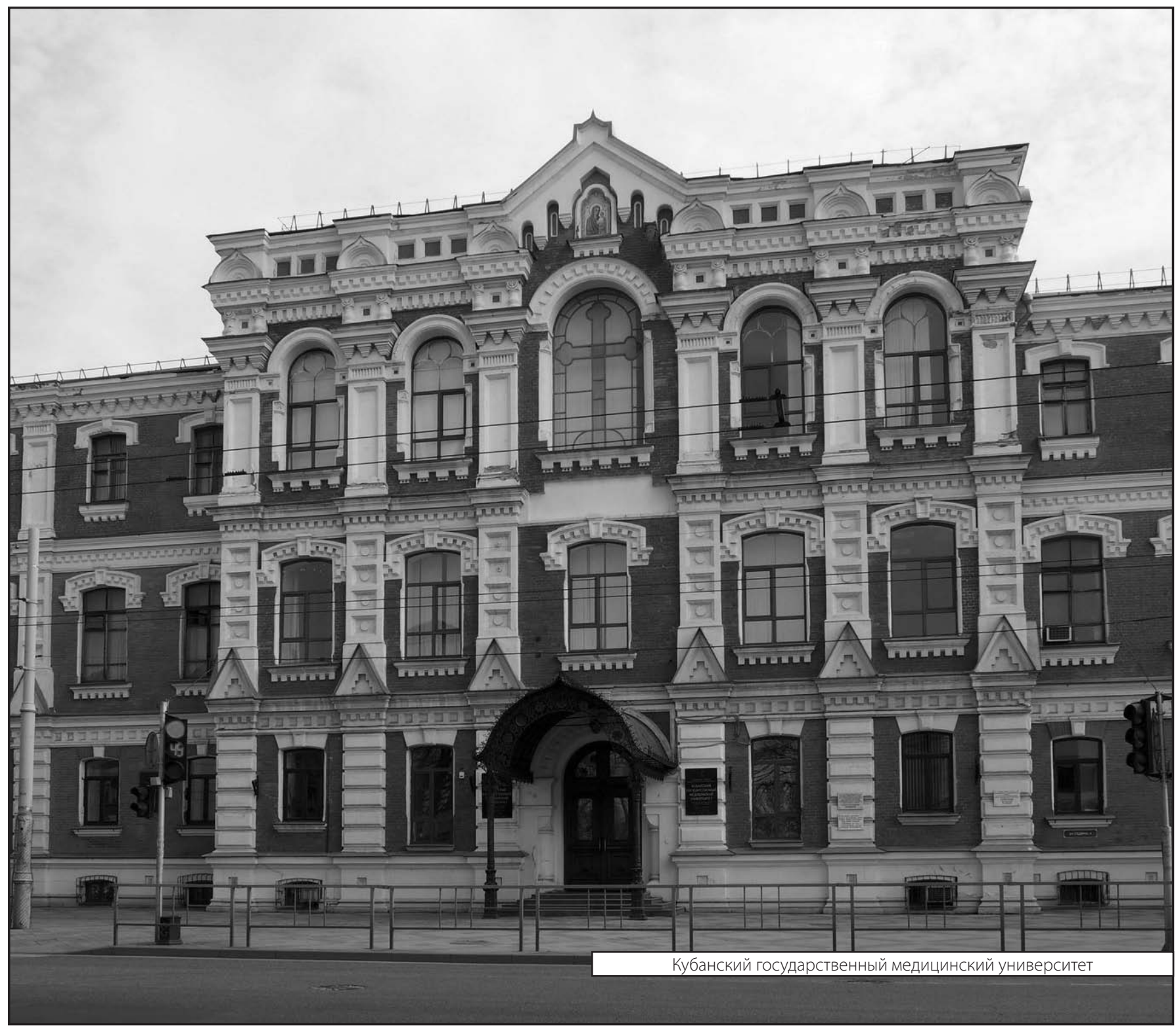

